\title{
The Implementation of Information Technology in the Clinical Practice Lesson
}

\author{
Jin-guo Wang ${ }^{1}, \mathrm{Na}$ Wang $^{2, *}$ \\ ${ }^{1}$ Department of Urology, The First Hospital of Jilin University, China \\ ${ }^{2}$ Department of Anesthesiology, The First Hospital of Jilin University, China \\ ${ }^{*}$ Corresponding author
}

Keywords: Education Implementation, Information Technology, Clinical Practice.

\begin{abstract}
The effect of information technology for promotion of education reform is obvious. The application of modern education technology into clinical medical education has become an inevitable trend. On the base of an auxiliary digital teaching platform, information management of clinical practice course can improve efficiency and effectiveness of practice.
\end{abstract}

\section{Introduction}

In recent years, domestic universities including medical schools put in a lot of money to start the construction work of education information, the information technology into education, the teacher's teaching, the education teaching idea, theory and method, method, model of fundamental change. With information technology to promote medical education teaching reform, the effect of applying modern education technology to the teaching of the medical education has become an inevitable trend.

\section{The Significance of Clinical Practice of Medical Students}

Clinical practice is an important part of medical higher education. From students to doctors' transformation, the crucial stage of transition from theory to practice. To medical students' future career play an immeasurable role. And there are very few hospitals for clinical medical teaching to introduce or develop specialized digital and information-based teaching platform; even if part of the hospital can use the digital platform of the school. Some of the educational administration, teaching quality assessment and evaluation function cannot be used directly. It can't meet the requirements of clinical teaching and management. The reason may be hospital network information platform can't compatible with colleges and universities platform. Such as many hospitals have the doctor workstation, HIS system, electronic medical record system, medical quality control system and so on information system, but generally for safety problems that can only be used in the hospital Intranet [1]. Basic does not have special network interface and colleges and universities is same. Choose the appropriate digital auxiliary teaching platform while at present many medical colleges have to carry out the digital campus information platform construction, etc. Bear the affiliated hospital of clinical medical teaching, teaching hospital rarely use the modern technology.

\section{The Advantage of IT-based Education}

In recent years, the state advocates the information teaching, network teaching as the core of the information-based teaching has already thorough popular feeling, all medical university, the construction of a large number of network teaching courses, to enhance the level of information teaching has played a great role in promoting. Relevance, autonomy and situation are outstanding characteristic of real-time and interaction, etc, especially suitable for medical teaching. Its application in the medical education to continue education of clinical doctors and teachers can access this information at any time, to effectively track the patient's treatment process and learn the training 
process of cattle. Help continue education of clinical doctors in clinical work, greatly improving the clinical effect of learning. Using a mobile phone on a remote server related data, to deal with the difficulties encountered in the actual work, take a good practical effect [2].

At the same time also should see, though up to the school teaching management institution, down to the basic unit of teaching, education technology department to pay a lot of effort and hard work. But the actual use effect is not satisfactory. Reason is various, such as network curriculum content is limited, the update is slow, interactivity is not strong, the relative lack of hardware facilities.

There is another reason that hospital is various, learning the schedule is very compact, clinical medical students can free time very little, clinical education can only be conducted by the stipulated time fixed cable network online learning, teachers are often organizations continue to education of clinical medical students on online learning together, make the network teaching lose the advantages of autonomous learning, learning effect [3].

\section{The Construction of Mobile Medical Teaching Platform}

Relying on a network and mature in the existing hospital management information system. It includes hospitals, the classroom, the teacher's office, a library, a doctor's office, the nurse station. Even the wards, so clinicians can call at any time learning resources, upload study records participate in the teaching effect test, online discussions answering questions and operation management. Teachers can use this platform release their teaching plan, electronic lesson plans, multimedia courseware, and homework assignments can also use this platform to clinical doctors communicate more freedom, so as to promote its effective autonomous learning, inquiry learning and collaborative learning, and to evaluate the effect of learning [4]. The traditional teaching and network teaching to the mobile terminal environment migration, construction into a set of teaching organization, resource distribution, teaching management and teaching service is a body comprehensive information platform.

\section{The Improvement Measures}

Boundary pulse learning theory emphasizes the learners' inner world to learn the importance of great importance to the existing knowledge structure, learning motivation, learning interest analysis. If the situated cognition and learning theory emphasizes the social and cultural situation is a kind of external learning environment, so in pulse learning theory emphasizes the learners themselves the original memory, experience, motivation and reaction is a kind of internal learning environment. And based on lectures, discussions and social learning activities such as social knowledge gained by the extensive and in-depth, and spend less time, don't need too much perseverance. Micro strategy under the guidance of the design is one of mobile learning course. It is the laws and characteristics of the combination of adult learning [5]. Design and production of mini course content meet the demand of mobile learning anytime and anywhere.

That for a limited time in the study is relatively short, loosely connected, self-contained knowledge content or module. It is a kind of can use mobile communication technology to realize two-way communication way of learning. Often mobile terminal is the carrier, such as portable mobile devices. By strengthening the students' positive guidance, teaching effect is significantly improved. Doctor for this kind of specific design of the special features of adult learners, embodies the practical and not the pursuit of the characteristics of the system the most important.

\section{The Problems Existing in the Clinical Practice}

Clinical work hard, make many departments and teaching of teachers and students lack adequate communication and interaction. The management of the interns and evaluation has become a mere formality, and part of the medical students' own enthusiasm is not high, only pay attention to the examination link and ignores the usual practice, the practice effect is not satisfactory. Problems in 
clinical practice because of the medical students mainly worked as an intern in various clinical departments. The hospital management of internship teaching management department only can depend on the desk [6]. The practice of teaching and learning are the lack of effective regulatory measures and objective evaluation index.

As a result of the existence of objective data, the student will see a gap between each other. Appropriate to increase the learning pressure, thus forming a good learning atmosphere, lays the foundation for qualified medical personnel. Students think it is necessary to introduce information platform for practice teaching and management, think, teaching resources, can more easily believe that the communication between teachers and students more convenient, think to increase the fun of learning and initiative. Through discussion between teachers and students, answering module can be convenient interactive teaching. Students can get classmates and teachers online reply. To schools, hospitals, department relevant documents in the file module for interns, students can refer to in a timely manner. Platform and classification repository can show the practice teaching outline, teaching courseware, lesson plans, question bank, video recording, the resources of teaching resources, etc.

\section{Platform for Both Students and Teachers}

Many students use the platform to carry out a study and help each other, such as mutual medical records, and discussing cases, improve the efficiency and effectiveness of practice as well. Through the information teaching and management, students learn to active learning opportunities to mining. Get to me before as active.

The use of information platform makes teaching a more objective quantitative evaluation. We can clearly know what need to teach. How can people be taught requirements, improve the teaching consciousness. Teachers think it is necessary in practice to carry out the information of teaching and management, improve the teaching efficiency and effect, increases the chances of the way to interact with students and, to dynamically grasp the learning situation of students, improve teaching consciousness [7]. At the same time, because the student assessment and supervision. Students internship effect will directly affect the teaching of the teacher's evaluation, also to a certain extent, to strengthen the teaching of the teacher's enthusiasm, by comparing with each other, form a good teaching atmosphere.

\section{The Inspection}

Excellent teaching team construction is an important technical support. Information teaching platform is also the realization of digital publishing and teaching of national ministry of education advocates quality engineering construction, national fine course construction of important technical support. The reform in the past only to unified organization theory, skills assessment scores as students' internship performance. The situation of students' internship at ordinary times changes past students pay attention to the phenomenon of the exam and ignore the quality of internship at ordinary times. After the completion of the digital teaching platform to a great extent, it is convenient for students' autonomy, cooperative, exploratory learning. It can effectively help teachers to improve teaching effect and teaching efficiency and teaching activities. Also it is convenient for teachers of high quality teaching resources share accumulation.

\section{Conclusions}

Digital and information-based teaching effectively implement student-centered interaction between teachers and students, adapting to the socialization of medical education to lifelong education, the innovation quality education and student-centered education the need of the change of the pattern. Digital and information-based teaching, it is not only the modernization of medical education requirements, but also the sign of modernization of medical education. 


\section{References}

[1] Stuckey B. Making the Most of the Good Advice: Meta-analysis of Guidelines for Establishing an Internet-Mediated Community of

http://www.bronwyn.ws/publications/papers/good_advice. pdf. 2009

[2] Schlager M, Fusco J., Schank P. Evolution of an online education community of practice. 2002

[3] ACGME, ABMS. Joint Initiative Attachment: Toolbox of Assessment Methods, Version 1. 2000

[4] Collins A, Brown J, Holum A. Cognitive apprenticeship: Making thinking visible. American Educator. 1991

[5] Collins A, John S, Holum A. Cognitive Apprenticeship: Making Thinking Visible. http://www.21leam.org/arch/articles/brown_seely.html/. 2010

[6] Collins A, Brown J, Newman S. Congnitive apprenticeship: Teaching the crafts of reading, writing, and mathematics. American Educator. 1989

[7] Cash J, Behrmann M. Effectiveness of Cognitive Apprenticeship Instructional Methods in College Automotive Technology Classrooms. Journal of Industrial Teacher Education. 1997 